\title{
Association of 25-hydroxyvitamin D with cardiometabolic risk factors and metabolic syndrome: a mendelian randomization study
}

\author{
Chi Chen, Yi Chen, Pan Weng, Fangzhen Xia, Qin Li, Hualing Zhai, Ningjian Wang ${ }^{*}$ and Yingli Lu* (B)
}

\begin{abstract}
Background: Low circulating vitamin D levels have been associated with increased risk of metabolic syndrome (MS) and cardiometabolic risk factors in multiple epidemiology studies. However, whether this association is causal is still unclear. We aimed to test whether genetically lowered vitamin D levels were associated with MS and its metabolic traits, using mendelian randomization (MR) methodology.

Methods: Ten thousand six hundred fifty-five participants were enrolled from the SPECT-China study, which was performed in 23 sites in East China during 2014 to 2016. Using four single-nucleotide polymorphisms (SNPs) in the DHCR7, CYP2R1, GC and CYP24A1 genes with known effects on 25(OH) D concentrations, we created a genetic risk score (GRS) as instrumental variable (IV) to estimate the effect of genetically lowered 25(OH) D on MS and cardiometabolic risk factors. MS was defined according to the International Diabetes Federation criteria.

Results: Lower measured 25(OH)D levels were associated with MS (OR 0.921,95\% Cl 0.888, 0.954) after multivariable adjustment. However, the MR-derived odds ratio of genetically determined $25(\mathrm{OH}) \mathrm{D}$ for risk of MS was 0.977 (95\% Cl 0.966, 1.030). The MR-derived estimates for raised fasting plasma glucose was 0.578 ( $95 \% \mathrm{Cl} 0.321,0.980)$ per $10 \mathrm{nmol} / \mathrm{L} \mathrm{GRS}_{\text {synthesis }}$ determined increase of 25(OH) D levels.

Conclusions: We found no evidence that genetically determined reduction in 25(OH)D conferred an increased risk of MS and its metabolic traits. However, we created our GRS only on the basis of common variants, which represent limited amount of variance in 25(OH)D. MR studies using rare variants, and large-scale well-designed RCTs about the effect of vitamin D supplementation on MS are warranted to further validate the findings.
\end{abstract}

Keywords: Vitamin D, Metabolic syndrome, Cardiometabolic risk factors, Mendelian randomization analysis

\section{Introduction}

Metabolic syndrome (MS) is defined by an aggregation of cardiometabolic risk factors, including central obesity, hypertension, impaired glucose regulation, elevated triglycerides, and decreased high-density lipoprotein cholesterol that predispose the subject to developing multiple chronic diseases [1]. The prevalence of MS is increasing rapidly worldwide and it is estimated by the International Diabetes Federation that one quarter of the world's adult

\footnotetext{
*Correspondence: wnj486@126.com; luyingli2008@126.com Institute and Department of Endocrinology and Metabolism, Shanghai Ninth People's Hospital, Shanghai JiaoTong University School of Medicine, Shanghai 200011, China
}

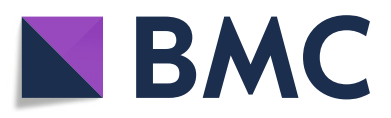

(c) The Author(s). 2019 Open Access This article is distributed under the terms of the Creative Commons Attribution 4.0 International License (http://creativecommons.org/licenses/by/4.0/), which permits unrestricted use, distribution, and reproduction in any medium, provided you give appropriate credit to the original author(s) and the source, provide a link to the Creative Commons license, and indicate if changes were made. The Creative Commons Public Domain Dedication waiver (http://creativecommons.org/publicdomain/zero/1.0/) applies to the data made available in this article, unless otherwise stated. was $33.9 \%$ (31.0\% in men and $36.8 \%$ in women), which indicates that about 454 million adults were affected [3].

Vitamin D deficiency is also a global pandemic health problem and has been associated with MS and its metabolic traits in numerous cross-sectional studies [4-6]. However, it is still uncertain whether the observed association is causal or owing to confounding or reverse causation. In a dose-response meta-analysis by Sang Yhun Ju et al. [7], the association between lower Vitamin D status and risk of MS was only existed in cross-sectional studies, not in longitudinal studies. A most recent cross-sectional study found that adjusted odds ratios (OR) of MS in the 
fourth compared with the lowest quartile for serum 25(OH)D levels was 0.48 (95\% CI 0.28-0.84) [8]. Clinical trials exploring the effect of vitamin $\mathrm{D}$ supplementation on cardiometabolic disorders were limited and failed to demonstrate a simultaneous protective effect [9-11]. Thus, the causality between vitamin D and MS and its components has not been confirmed in human beings.

Mendelian randomization (MR) uses genetic variants associated with an intermediate phenotype [in the present study, 25-hydroxyvitamin D (25(OH)D)] as instrumental variables (IVs) in non-experimental data to derive causal inferences about the effect of an exposure on an outcome [12]. In this study, if low $25(\mathrm{OH}) \mathrm{D}$ causally leads to MS, genetic variants associated with lower 25(OH)D should be associated with higher risk of MS and its metabolic traits [13]. Because genetic variants are randomly allocated at the time of gamete formation and assigned prior to outcome and confounders, MR studies are conceptually similar to randomized controlled trials (RCTs) and can overcome limitations in observational studies such as residual confounding and reverse causation [14]. Further, recent progresses in genotyping enable the application of MR approach in sample sizes that are not realistic for RCTs of vitamin D supplementation.

Using data from a large community-based sample of participants from the SPECT-China study (survey on prevalence in East China for metabolic diseases and risk factors), we investigated the association of $25(\mathrm{OH}) \mathrm{D}$ with cardiometabolic risk factors and MS. We inferred causality by using vitamin D genetic risk scores (VD_GRS) as IVs by MR analyses.

\section{Methods}

\section{Study population}

Figure 1 shows the study design. We analyzed the observed associations between measured variables (residual confounding and reverse causation) and genetic associations between genotypes and measured variables (no residual confounding or reverse causation). First, we assessed the association between vitamin $\mathrm{D}$ related genetic variants and 25(OH)D concentrations (Fig. 1a). Second, we measured the effects of genetic variants associated with $25(\mathrm{OH}) \mathrm{D}$ on the changes of metabolic components and MS risk (Fig. 1c). Third, we did observational assessments of the relation between $25(\mathrm{OH}) \mathrm{D}$ concentrations and present MS and its components (Fig. 1b).

SPECT-China study population was used to describe the relationship between GRS and 25(OH)D levels, and to obtain IV results on the causal effect of 25(OH)D levels on MS and related traits. SPECT-China is an ongoing population-based cross-sectional study of 12,666 randomly selected community-dwelling individuals. Recruitment has been described in detail in previous papers [15-17]. Briefly, we used a stratified cluster sampling method to select a sample in the general population. The sampling process was stratified according to rural/urban area and economic development status. Random sampling was completed before data collection. From 2014 to 2016, the participants from 18 to 93 years in age were recruited from 23 sites in Shanghai, Zhejiang, Jiangsu, Anhui and Jiangxi provinces. Among them, 10,661 (84.2\%) participants had genotype

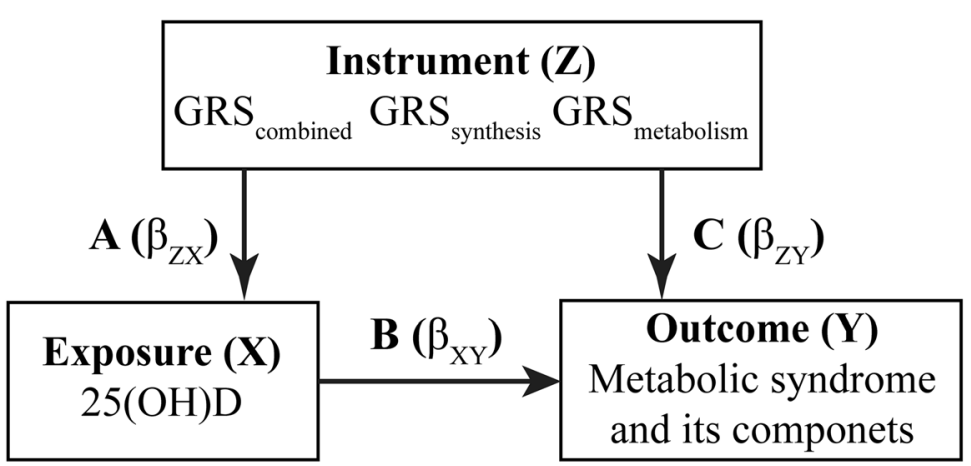

$$
\begin{aligned}
& \beta_{\mathrm{IV}}=\beta_{\mathrm{ZY}} / \beta_{\mathrm{ZX}} \\
& 95 \% \mathrm{CI}_{\mathrm{IV}}=\beta_{\mathrm{IV}} \pm 1.96 * \mathrm{SE}_{\mathrm{IV}} \\
& \mathrm{SE}_{\mathrm{IV}}=\operatorname{abs}\left(\beta_{\mathrm{IV}}\right) \sqrt{\left(\frac{\mathrm{SE}_{\mathrm{GRS} \text { exposure }}}{\beta_{\mathrm{GRS} \text { _exposure }}}\right)^{2}+\left(\frac{\mathrm{SE}_{\mathrm{GRS} \text { outcome }}}{\beta_{\mathrm{GRS} \text { _outcome }}}\right)^{2}}
\end{aligned}
$$

Fig. 1 Study design and tested associations. GRS, genetic risk score; 25(OH)D, 25-hydroxyvitamin D; IV, instrumental variable. We assessed the association between vitamin D related genetic variants and 25(OH)D concentrations (a). Second, we measured the effects of genetic variants associated with $25(\mathrm{OH}) \mathrm{D}$ on the changes of metabolic components and MS risk (c). Third, we did observational assessments of the relation between $25(\mathrm{OH}) \mathrm{D}$ concentrations and present MS and its components (b) 
information of vitamin D single nucleotide polymorphisms (SNPs). Participants who had missing information on more than two SNP genotypes $(n=4)$ and 25(OH)D $(n=2)$ were excluded. The current study sample included 10,655 participants.

The Ethics Committee of Shanghai Ninth People's Hospital, Shanghai JiaoTong University School of Medicine approved the study. The study was conducted in compliance with the principles of the 1975 Declaration of Helsinki as reflected in a priori approval by the appropriate institutional review committee. Informed written consent was obtained from all participants recruited in the study.

\section{Measurements}

In each study site, the same staff performed all data collection. They were trained according to a standard protocol that made them familiar with the specific tools and methods used. The same trained staff used the standardized and validated questionnaire to collect information on socio-demographic information, medical and family history, general health, medication, etc.

Weight, height, waist circumference and BP were assessed by standard methods [18]. Body mass index (BMI) was calculated as weight in kilograms divided by height in meters squared. Current smoking was defined as having smoked at least 100 cigarettes in one's lifetime and currently smoking cigarettes [18]. Each site was categorized into high and low economic status, comparing local gross domestic product per capita with the national one in 2013 [15].

Fasting plasma glucose (FPG), triglycerides (TG) and high density lipoprotein (HDL) were measured using the AU 680 (Beckman Coulter, Brea, USA). The 25(OH)D was detected using a chemiluminescence assay (ADVIA Centaur XP, Siemens, Germany). The 25(OH)D was detected by investigators who were blinded to phenotypic and genotypic data, and measured with chemiluminescenceassay (SiemensADVIA Centaur XP, Germany). The detection range of the assay for $25(\mathrm{OH}) \mathrm{D}$ is 10.5 $375 \mathrm{nmol} / \mathrm{L}[19]$.

\section{MS definition}

MS was determined based on the 2005 revision of the criteria from the National Cholesterol Education Program Adult Treatment Panel III [20]. A person with MS must have: abdominal obesity (waist circumference: male $\geq 90 \mathrm{~cm}$, female $\geq 80 \mathrm{~cm}$, or BMI is $\geq 30 \mathrm{~kg} / \mathrm{m}^{2}$ ) plus at least two of the following criteria: (i) Raised TG $>1.7$ $\mathrm{mmol} / \mathrm{L}$, or treatment for this dyslipidemia; (ii) Reduced $\mathrm{HDL}-\mathrm{C}<1.03 \mathrm{mmol} / \mathrm{L}$ in men or $<1.29 \mathrm{mmol} / \mathrm{L}$ in women, or treatment for this dyslipidemia; (iii) Raised BP: systolic BP $\geq 130$ or diastolic $\mathrm{BP} \geq 85 \mathrm{mmHg}$, or treatment for hypertension; (iv) Raised FPG $\geq 5.6 \mathrm{mmol} / \mathrm{L}$ or a history of type 2 diabetes.

\section{Genotyping, genetic loci selection and genetic risk score construction}

DNA was extracted from peripheral white blood cells using a blood genomic DNA extraction kit (DP603, TIANGEN BIOTECH CO, LTD, Beijing, China) on an automated nucleic acid extraction instrument (YOSE-S32, TIANGEN BIOTECH CO, LTD, Beijing, China). Specific assays were designed using Geneious Pro (v4.8.3) (https:// www.geneious.com/). Mass determination was performed using the JUNO and data acquisition was completed with Fluidigm SNP Genotyping Analysis v4.1.3 software (Fluidigm Corporation, South San Francisco, California, USA). Genotyping was performed blinded to $25(\mathrm{OH}) \mathrm{D}$ and cardiometabolic profile. Call rates for all SNPs were greater than $98 \%$.

The four vitamin D-related SNPs [DHCR7 (related to vitamin D synthesis) rs12785878, CYP2R1 (hepatic 25hydroxylation) rs10741657, GC (transport) rs2282679, and CYP24A1 (catabolism) rs6013897] were chosen on the basis of a recent MR study containing Asian participants [21]. These SNPs were also used in previous mendelian analyses in Chinese [22, 23]. They all achieved a genome-wide significance level in genome-wide association studies $\left(P<5 \times 10^{-8}\right)$ and showed no sign of linkage disequilibrium $\left(r^{2}=0\right)$. The full list of each SNP was displayed in Additional file 1:Table S1.

\section{Statistical analysis}

All statistical analyses were undertaken using IBM SPSS Statistics, Version 22 (IBM Corporation, Armonk, NY, USA). All analyses were two-sided. A $P$ value $<0.05$ indicated significance. Continuous and categorical variables were expressed as the mean \pm standard deviation (SD) and as percentages (\%), respectively. Additive models with MS and related metabolic traits as outcomes were adjusted for age, sex, urban/rural residence, economic status, current smoking, waist circumference, diabetes, hypertension, HDL-cholesterol and ln (triglycerides); models with $25(\mathrm{OH}) \mathrm{D}$ concentration as the outcome were additionally adjusted for season of sampling.

The additive genetic model for each SNP was used to construct GRS. Each SNP was coded 0-2 based on the number of effect alleles and then multiplied by the $\beta$ value from the previous study [21], followed by summing the four values. In one SNP, those missing ones were assigned the median score $(0,1$ or 2$)$. We not only cal-

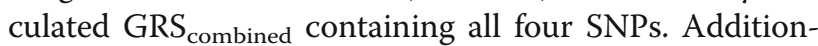
ally, we did separate mendelian randomization analyses using GRSs for SNPs for 25(OH)D synthesis (DHCR7 and CYP2R1) and metabolism (GC and CYP24A1).

We first assessed the association of each SNP with $25(\mathrm{OH}) \mathrm{D}$ concentration using linear regression. Then, we examined associations of each SNP with metabolic 
syndrome and its components. Serum TG was logarithmically transformed prior to analysis.

For the main mendelian randomization analysis, linear regression analyses were used to determine the association estimates $\left(\boldsymbol{\beta}_{\mathrm{Zx}}\right)$ of $\mathrm{GRS}_{\text {combined }}, \mathrm{GRS}_{\text {synthesis }}$ and $\mathrm{GRS}_{\text {metabolism }}$ with $25(\mathrm{OH}) \mathrm{D}$. We also assessed the strength of associations using $F$-statistics $\left[F=\left(\mathrm{R}^{2 *}(\mathrm{n}-2)\right) /\right.$ $\left(1-\mathrm{R}^{2}\right)$ ] [24]. $F$ values greater than 10 were regarded as strong enough for MR analysis [25]. Then, we examined the association $\left(\boldsymbol{\beta}_{\mathrm{ZY}}\right)$ of $\mathrm{GRS}_{\text {combined }}$, $\mathrm{GRS}_{\text {synthesis }}$ and

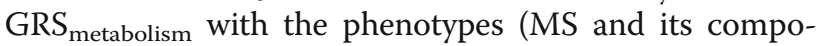
nents) using linear regression for continuous variables and logistic regression for binary variables.

To explore the observational association $\left(\boldsymbol{\beta}_{\mathbf{X Y}}\right)$ of $25(\mathrm{OH}) \mathrm{D}$ on phenotypes (MS and its components), We generated linear regression models for continuous outcomes (e.g., waist circumference) and logistic regression models for binary outcomes (e.g., MS). Effect estimates were presented per $10 \mathrm{nmol} / \mathrm{L}$ increase in $25(\mathrm{OH}) \mathrm{D}$.

We used the GRSs as the IVs to estimate the causal effect of 25(OH)D on the same outcome diseases and measures. We calculated IV estimates of genetically determined $\beta$ coefficients or odds ratios (OR) with the Waldtype estimator [25]. For continuous outcomes (waist circumference, FPG, lnTG, HDL and blood pressure), the computational formula was $\beta_{\mathrm{IV} \text { (VD-outcome })}=\beta_{\mathrm{GRS} \text {-outcome }} /$ $\beta_{\text {GRS-VD }}$. For dichotomous outcomes (central obesity, raised fasting plasma glucose, triglyceride and blood pressure, reduced HDL and MS), the computational formula was $\mathrm{OR}_{\mathrm{IV} \text { (VD-outcome) }}=\exp$. $\left(\ln \left(\mathrm{OR}_{\mathrm{GRS} \text {-outcome }}\right) / \beta_{\mathrm{GRS}-\mathrm{VD}}\right)$.

In the sensitivity analyses, we used another IV calculating method, a two-stage regression estimator to calculate causal $\beta$ coefficients or ORs per $10 \mathrm{nmol} / \mathrm{L}$ increase in $25(\mathrm{OH}) \mathrm{D}$ [26]. In the first stage, a linear regression of $25(\mathrm{OH}) \mathrm{D}$ on GRSs was used to generate $25(\mathrm{OH}) \mathrm{D}$ fitted values. In the second stage, The predicted $25(\mathrm{OH}) \mathrm{D}$ values from the first stage were used for linear and logistic regression analyses with the metabolic traits and MS as the dependent variable.

\section{Results}

The study comprised 10,655 participants from general population who had detailed metabolic profiles measured and information on gene score for predisposition to decreased $25(\mathrm{OH}) \mathrm{D}$. In them, $60.0 \%$ were women, and all were of Asian descent. The mean age was 54.9 (SD 12.9) $\mathrm{y}$, and mean waist circumference and $25(\mathrm{OH}) \mathrm{D}$ was 81 (SD 10) $\mathrm{cm}$ and 40.6 (SD 12.8) $\mathrm{nmol} / \mathrm{L}$ at the time of clinical assessment. The prevalence of MS was $27.8 \%$.

\section{Association of SNPs with 25(OH)D and MS}

We tested the association of four vitamin D-related SNPs with $25(\mathrm{OH}) \mathrm{D}, \mathrm{MS}$ and related metabolic traits (Additional file 1: Table S2). In the four vitamin D-related
SNPs, all four effect alleles showed an inverse linear relationship with 25(OH)D level and two had significant associations (GC and $D H C R$ ) after adjusting for age, sex, urban/rural residence, economic status and current smoking. None of the $25(\mathrm{OH}) \mathrm{D}$ related SNPs were significantly associated with MS or its metabolic traits including waist circumference, FPG, lnTG, HDL, blood pressure.

\section{Study characteristics according to $\mathrm{GRS}_{\text {combined }}$}

As expected, with increasing quartiles of VD_GRS, $25(\mathrm{OH}) \mathrm{D}$ concentrations significantly decreased in both men and women (Table 1). Univariable linear regression demonstrated a strong relationship between GRSs and $25(\mathrm{OH}) \mathrm{D}$ level $\left(\beta_{\mathrm{ZX}}\right)$. Each 1 unit increment of GRS com- $_{\text {- }}$ bined, GRS $_{\text {synthesis }}$ and GRS metabolism was associated with a decrease of 0.976 ( $95 \%$ CI $0.806,1.146), 0.838$ (95\% CI $0.597,1.078)$ and $1.319(95 \% \mathrm{CI} 1.063,1.575) \mathrm{nmol} / \mathrm{L}$ in 25(OH)D levels, respectively (Fig. 2). The F-statistic of $\mathrm{GRS}_{\text {combined }}, \mathrm{GRS}_{\text {synthesis }}$ and GRS metabolism was 107.6, 32.1 and 96.7, respectively, indicating strong IVs for MR.

The calculated risk score $\mathrm{GRS}_{\text {combined }}$ was neither consistently associated with any of the investigated MS components such as blood lipids, BP, or waist circumference, nor with other risk factors such as age, sex, smoking, and economic status, except for an association with FPG in men. There was also no association with the prevalence of MS.

\section{Associations of 25(OH)D and GRSs with MS}

Regarding the cross-sectional associations of 25(OH)D with metabolic syndrome traits (continuous variables) $\left(\beta_{\mathrm{XY}}\right)$, lnTG was negatively associated with $25(\mathrm{OH}) \mathrm{D}$ (0.059 decrease per $10 \mathrm{nmol} / \mathrm{L}$ increase in $25(\mathrm{OH}) \mathrm{D})$, but both systolic and diastolic blood pressure showed positive association with $25(\mathrm{OH}) \mathrm{D}$. Waist circumference, FPG and HDL showed no significant association (Table 2). The cross-sectional associations with metabolic syndrome components (dichotomous variables) $\left(\mathrm{OR}_{\mathrm{XY}}\right)$ were coherent with metabolic syndrome traits (Table 3). Metabolic syndrome was negatively associated with 25(OH)D (OR 0.921, 95\% CI 0.888, 0.954).

Regarding $\beta_{\mathrm{ZY}}$, one unit increase in VD_GRS, VD_ GRS $_{\text {metabolism }}$, and VD_GRS synthesis $_{\text {was }}$ not significantly associated with metabolic syndrome traits (continuous variables), except that $\mathrm{GRS}_{\text {combined }}$ and $\mathrm{GRS}_{\text {synthesis }}$ showed marginally significant association with FPG $(P=$ 0.086 and 0.061 , respectively) (Table 2). For dichotomous variables, $\mathrm{GRS}_{\text {synthesis }}$ showed significant association with raised FPG (OR 1.047, 95\% CI 1.001, 1.095) and other associations were in accordance with those with continuous variables (Table 3 ).

\section{5(OH)D and MS: the MR analysis}

The causal effects of 25(OH)D on the MS and its traits were analyzed using MR (Tables 2 and 3). Although 
Table 1 Characteristics of study participants according to the weighted vitamin D genetic risk score $\left(\mathrm{GRS}_{\text {combined }}\right)$ stratified by gender $(n=10655)$

\begin{tabular}{|c|c|c|c|c|c|}
\hline \multirow[t]{2}{*}{ Characteristic } & \multicolumn{4}{|l|}{$\mathrm{GRS}_{\text {combined }}$} & \multirow{2}{*}{$\begin{array}{l}P \text { for } \\
\text { trend }\end{array}$} \\
\hline & Quartile 1 & Quartile 2 & Quartile 3 & $\overline{\text { Quartile } 4}$ & \\
\hline \multicolumn{6}{|l|}{ Men } \\
\hline $\mathrm{GRS}_{\text {combined }}$ & $\leq 2.480$ & $2.481-3.520$ & $3.521-4.640$ & $\geq 4.641$ & \\
\hline N & 1072 & 1066 & 995 & 952 & \\
\hline Age, yr & $55.5(13.2)$ & $55.5(13.2)$ & $55.7(13.1)$ & $55.8(13.0)$ & 0.547 \\
\hline $25(\mathrm{OH}) \mathrm{D}, \mathrm{mmol} / \mathrm{L}$ & $45.3(14.1)$ & $44.0(13.3)$ & $42.7(13.6)$ & $41.5(12.7)$ & $<0.001$ \\
\hline Fasting plasma glucose, $\mathrm{mmol} / \mathrm{L}$ & $5.67(1.43)$ & $5.72(1.54)$ & $5.76(1.63)$ & $5.87(1.81)$ & 0.005 \\
\hline Body mass index, $\mathrm{kg} / \mathrm{m}^{2}$ & $25.0(3.4)$ & $24.9(3.4)$ & $25.0(3.6)$ & $25.0(3.5)$ & 0.719 \\
\hline Waist circumference, $\mathrm{cm}$ & $85.1(9.9)$ & $85.2(9.2)$ & $85.1(9.5)$ & $85.3(9.5)$ & 0.714 \\
\hline Triglycerides, mmol/L & $1.85(1.93)$ & $1.85(1.95)$ & $1.91(1.93)$ & $1.91(1.60)$ & 0.345 \\
\hline High-density lipoprotein, mmol/L & $1.32(0.32)$ & $1.33(0.32)$ & $1.33(0.33)$ & $1.31(0.31)$ & 0.566 \\
\hline Systolic blood pressure, $\mathrm{mmHg}$ & $135(21)$ & $134(20)$ & $135(21)$ & $134(21)$ & 0.731 \\
\hline Diastolic blood pressure, $\mathrm{mmHg}$ & $82(13)$ & $82(13)$ & $82(13)$ & $82(13)$ & 0.224 \\
\hline Current smoker, \% & 44.1 & 44.7 & 45.2 & 46.9 & 0.712 \\
\hline Central obesity, \% & 31.8 & 32.6 & 32.1 & 33.2 & 0.579 \\
\hline Raised fasting plasma glucose, $\%$ & 36.6 & 38.1 & 39.8 & 42.0 & 0.006 \\
\hline Raised triglycerides, $\%$ & 42.1 & 44.4 & 43.9 & 42.9 & 0.796 \\
\hline Reduced high-density lipoprotein, $\%$ & 25.3 & 26.0 & 26.3 & 28.4 & 0.105 \\
\hline Raised blood pressure, $\%$ & 67.8 & 68.9 & 68.6 & 65.7 & 0.286 \\
\hline Metabolic syndrome, \% & 21.9 & 25.0 & 24.4 & 23.7 & 0.416 \\
\hline Rural/urban residence, $\%$ & $49.3 / 50.7$ & $49.2 / 50.8$ & $49.7 / 50.3$ & $48.9 / 51.1$ & 0.936 \\
\hline Low/high econmic status, \% & $33.9 / 66.1$ & $34.2 / 65.8$ & $35.7 / 64.3$ & $36.7 / 63.3$ & 0.129 \\
\hline \multicolumn{6}{|l|}{ Women } \\
\hline $\mathrm{GRS}_{\text {combined }}$ & $\leq 2.440$ & $2.441-3.480$ & $3.481-4.640$ & $\geq 4.641$ & \\
\hline N & 1601 & 1189 & 1493 & 1418 & \\
\hline Age, yr & $54.0(12.8)$ & $54.4(12.9)$ & $54.5(12.8)$ & $54.7(12.3)$ & 0.120 \\
\hline Premenopausal women, $\%$ & 47.7 & 47.4 & 46.1 & 45.3 & 0.161 \\
\hline $25(\mathrm{OH}) \mathrm{D}, \mathrm{mmol} / \mathrm{L}$ & $40.3(12.5)$ & $38.5(11.9)$ & $38.7(12.1)$ & $37.4(11.2)$ & $<0.001$ \\
\hline Fasting plasma glucose, $\mathrm{mmol} / \mathrm{L}$ & $5.58(1.43)$ & $5.62(1.43)$ & $5.61(1.46)$ & $5.57(1.32)$ & 0.868 \\
\hline Body mass index, $\mathrm{kg} / \mathrm{m}^{2}$ & $24.3(3.6)$ & $24.5(3.5)$ & $24.4(3.7)$ & $24.4(3.7)$ & 0.668 \\
\hline Waist circumference, $\mathrm{cm}$ & $78.3(9.8)$ & $78.9(9.8)$ & $78.6(10.1)$ & $78.5(9.6)$ & 0.592 \\
\hline Triglycerides, $\mathrm{mmol} / \mathrm{L}$ & $1.52(1.05)$ & $1.59(1.18)$ & $1.48(1.06)$ & $1.55(1.07)$ & 0.985 \\
\hline High-density lipoprotein, mmol/L & $1.44(0.31)$ & $1.45(0.31)$ & $1.47(0.32)$ & $1.45(0.32)$ & 0.238 \\
\hline Systolic blood pressure, $\mathrm{mmHg}$ & $131(22)$ & $132(21)$ & $131(22)$ & $132(22)$ & 0.258 \\
\hline Diastolic blood pressure, $\mathrm{mmHg}$ & $77(13)$ & $78(13)$ & $78(13)$ & $78(13)$ & 0.424 \\
\hline Current smoker, \% & 1.9 & 2.0 & 2.5 & 2.0 & 0.487 \\
\hline Central obesity, \% & 43.8 & 46.5 & 45.2 & 47.0 & 0.150 \\
\hline Raised fasting plasma glucose, $\%$ & 33.4 & 35.4 & 33.8 & 34.1 & 0.892 \\
\hline Raised triglycerides, $\%$ & 36.1 & 36.3 & 31.3 & 35.7 & 0.244 \\
\hline Reduced high-density lipoprotein, \% & 39.8 & 38.0 & 34.6 & 38.1 & 0.110 \\
\hline Raised blood pressure, $\%$ & 56.6 & 58.9 & 56.0 & 57.7 & 0.905 \\
\hline Metabolic syndrome, \% & 30.0 & 32.4 & 29.8 & 31.2 & 0.809 \\
\hline Rural/urban residence, $\%$ & $44.9 / 55.1$ & $45.8 / 54.2$ & $47.2 / 52.8$ & $46.9 / 53.1$ & 0.193 \\
\hline Low/high econmic status, \% & $32.5 / 67.5$ & $31.7 / 68.3$ & $32.4 / 67.6$ & $32.5 / 67.5$ & 0.910 \\
\hline
\end{tabular}




\begin{tabular}{|c|c|c|c|c|c|c|}
\hline & $\beta(95 \% C I)$ & $\boldsymbol{F}$ & & & & \\
\hline GRS $_{\text {combined }}$ & $-0.976(-1.146,-0.806)$ & 107.6 & & $\longmapsto$ & & \\
\hline GRS $_{\text {synthesis }}$ & $-0.838(-1.078,-0.597)$ & 32.1 & & $\longmapsto$ & & \\
\hline GRS $_{\text {metabolism }}$ & $-1.319(-1.575,-1.063)$ & 96.7 & $\longmapsto$ & $\longrightarrow$ & & \\
\hline . 2 Association between VD_GRS & רd 25-hydroxyvitamin D & & -1.5 & -1.0 & -0.5 & 0.0 \\
\hline
\end{tabular}

association was found between 25(OH)D concentration and InTG as well as systolic and diastolic blood pressure, the $95 \%$ confidence intervals $(95 \%$ CIs) of all calculated $\beta_{\mathrm{IV}} \mathrm{S}$ gave no evidence for rejecting the null hypothesis of no association, except that $25(\mathrm{OH}) \mathrm{D}$ genetically determined by $\mathrm{GRS}_{\text {combined }}$ and $\mathrm{GRS}_{\text {synthesis }}$ showed marginally significant association with FPG $\left(\beta_{\mathrm{IV}}-0.174,95 \% \mathrm{CI}\right.$ $-0.376,0.029, P=0.086$ and $\beta_{\mathrm{IV}}-0.32195 \% \mathrm{CI}-0.660$, $0.018, P=0.061$, respectively). Furthermore, MR analysis also found the association for raised FPG with $\mathrm{OR}_{\mathrm{IV}}$ of 0.578 (95\% CI $0.321,0.980)$ per $10 \mathrm{nmol} / \mathrm{L} \mathrm{GRS}_{\text {synthesis }}$ determined increase of $25(\mathrm{OH}) \mathrm{D}$ levels, but GRSs were not causally associated with the central obesity, raised TG, reduced HDL and raised blood pressure. Finally, the null association persisted in $25(\mathrm{OH}) \mathrm{D}$ and MS.

\section{Sensitivity analysis}

We also used a two-stage regression estimator to calculate the $\beta_{\mathrm{IV}}$ and $\mathrm{OR}_{\mathrm{IV}} \mathrm{S}$ per $10 \mathrm{nmol} / \mathrm{L}$ increase in $25(\mathrm{OH}) \mathrm{D}$ (Additional file 1: Tables S3 and S4). The results were rather similar to those using Wald-type estimator. The only significant association was also observed between 25(OH)D genetically determined by $\mathrm{GRS}_{\text {synthesis }}$ and raised FPG (OR 0.546, 95\% CI 0.302, 0.984 per $10 \mathrm{nmol} 25(\mathrm{OH}) \mathrm{D}$ increase).

\section{Discussion}

In this community-dwelling sample of Chinese adults, inverse cross-sectional associations between $25(\mathrm{OH}) \mathrm{D}$ and MS were observed after multivariate adjustment. However, the results of MR analysis provide no evidence that genetically lowered $25(\mathrm{OH}) \mathrm{D}$ is associated with increased risk of MS and its metabolic traits. The current study is, to our knowledge, the first MR study to investigate the effect of vitamin D on MS.

Most studies to date have reported cross-sectional associations of low vitamin D status with MS and its metabolic traits [4-6]. Although some studies indicated that optimization of vitamin D status could reduce some proatherogenic inflammatory markers and improve cardiometabolic profile $[9,27]$, meta-analyses of RCTs have consistently demonstrated no beneficial effects of vitamin D supplementation on cardiometabolic risk factors such as blood pressure [28], lipid profile [29] and cardiovascular diseases [30]. In line with our findings, two recent MR studies found that genetically reduced $25(\mathrm{OH}) \mathrm{D}$ is not associated with ischemic heart disease [31], coronary artery disease [32] and cardiovascular mortality [33].

Several possible reasons may explain the paradox of beneficial findings of observational studies versus disappointing results of RCTs and MR studies. First, residual confounding may account for a large part of the discrepancy. Though the association was significant in the cross-sectional setting, it may often still be a biased estimate, due to an inadequate control of potential confounders. Take outdoor physical activity for example: it is associated with cardiometabolic health [34] and solar exposure, which in turn influences vitamin D status. Second, low vitamin D status is an outcome, rather than a cause, of poor health (ie, reverse causation) [35]. Bidirectional MR studies suggest that the cardiometabolic risk factors, such as low density lipoprotein cholesterol, high remnant cholesterol and obesity may causally induce lower vitamin $\mathrm{D}$ status, whereas a lower $25(\mathrm{OH}) \mathrm{D}$ is unlikely to increase blood cholesterol and BMI [24, $36]$. That is, low serum $25(\mathrm{OH}) \mathrm{D}$ might be a consequence of a predisposition to cardiometabolic disorders rather than a cause of cardiometabolic diseases.

Interestingly, we observed that the synthesis allele score was significantly associated with increased risk of raised FPG, whereas the allele score for 25(OH)D metabolism was not. As we know, the DHCR7 gene converts 7-dehydrocholesterol to cholesterol, providing a substrate for vitamin D production. CYP2R1 plays a key role 


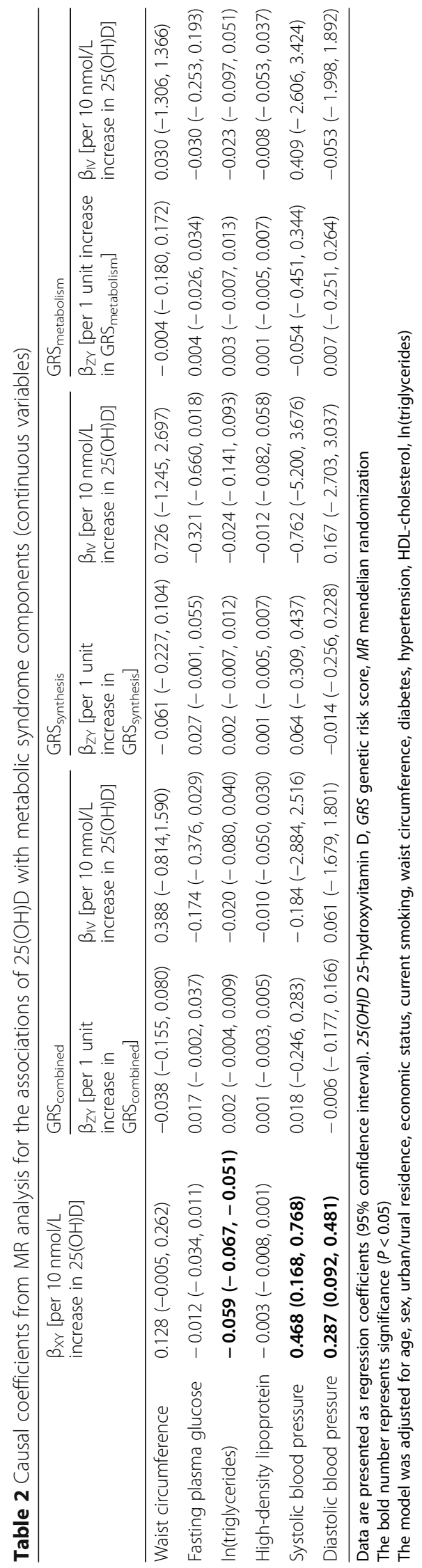




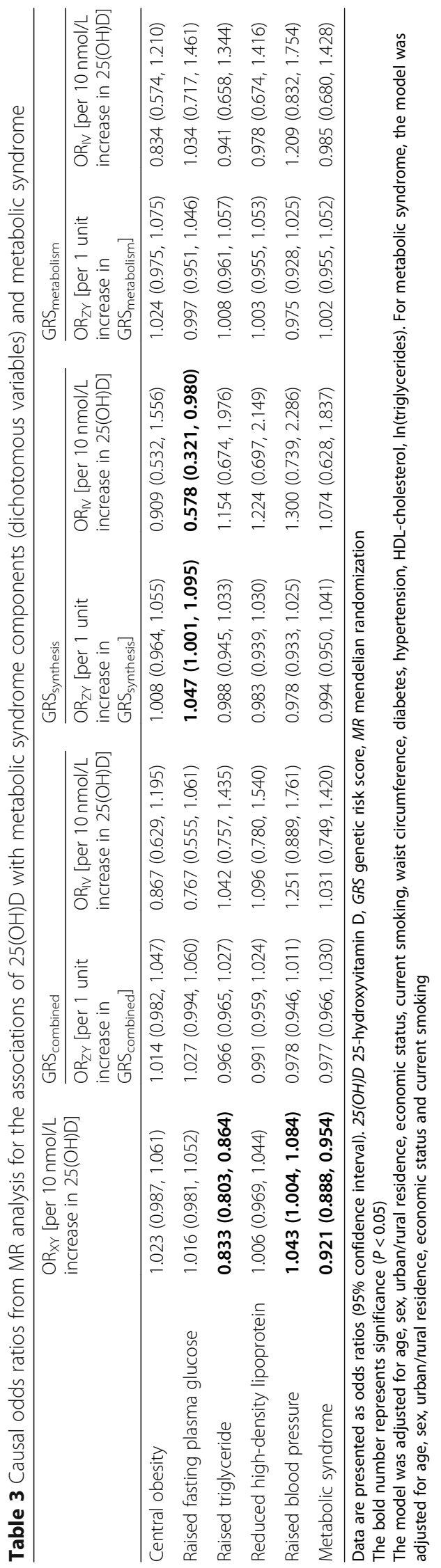


in 25-hydroxylation of vitamin D in the liver [37]. Thus, we may speculate that low vitamin D status via liver conversion from all sources (sunlight exposure, diet, and supplementation) is associated with raised FPG. Of note, genetically variants in DHCR7 and CYP2R1 have previously been demonstrated to be associated with increased risk of type 1 diabetes [38]. Specifically, GC encodes the vitamin $\mathrm{D}$ binding protein, which binds and transports $80-90 \%$ of $25(\mathrm{OH}) \mathrm{D}$ to target organs. CYP24A1 is responsible for degradation of 25(OH)D [39]. Consequently, components included in the metabolism allele score are of importance for the transfer and clearance of $25(\mathrm{OH}) \mathrm{D}$ and could provide insights into the influence of vitamin D metabolism on FPG. Nevertheless, the use of metabolism allele score as a formal instrument in MR analyses is susceptible to problems with regard to quantification of expected associations, pleiotropic effects, and metabolic feedback loops associated with the clearance of vitamin D-related metabolites by CYP24A1 [40]. Investigations with the vitamin $\mathrm{D}$ metabolism allele score were accordingly exploratory only. Last, we cannot rule out the possibility that the findings could have arisen by chance and should be replicated in further MR studies.

Considering cardiometabolic disease is the leading cause of death globally [41] and the sale of vitamin D supplements is increasing annually in older populations worldwide [42], our MR findings are relevant to clinical care. MR analyses using DHCR7, GC, CYP24A1, and CYP2R1 as IVs have been implemented in the past 5 years $[23,31,40,43]$. We and others recently provided evidence from MR that genetically reduced vitamin $D$ levels do not increase the risk of non-alcoholic fatty liver disease [23], type 2 diabetes mellitus [43] or ischemic heart disease [31], but might increase the risk of high blood pressure [40]. The present study also showed no evidence of a causal association between vitamin D and MS. In this regard, most association between vitamin D and cardiometabolic profile that seemed promising in observational studies did not withstand rigorous testing for causation in MR studies. Hence, vitamin D supplementation may not be a clinical priority in cardiometabolic disorders prevention.

The strength of our study was the relatively large sample of community-dwelling population, the MR study design, the detailed information on covariates and a created VD_GRS representing the combined effect of the established common genetic variations of $25(\mathrm{OH}) \mathrm{D}$ as the IV. In addition, the SNPs we used are a robust proxy for circulating levels of $25(\mathrm{OH}) \mathrm{D}$ and have well understood roles in vitamin D synthesis and metabolic pathway. Lastly, we did not detect any violations of the assumptions underlying MR as far as they could be tested.
However, there are several limitations we should acknowledge. Firstly, all participants were of Asian descent, and thus, our findings may not be necessarily generalizable to other ethnicities. Secondly, we created our VD_GRS only on the basis of common variants, which was considered to represent limited amount of variance in $25(\mathrm{OH}) \mathrm{D}$. We were unable to assess the potential contribution of rare variants. Lastly, we have no data of 1,25-dihydroxyvitamin $\mathrm{D}$, the active form of vitamin D metabolite leading to biological effects.

\section{Conclusion}

We found no evidence that genetically reduced 25(OH)D is associated with increased risk of MS and its metabolic traits. This suggests that the observed association of increased $25(\mathrm{OH}) \mathrm{D}$ with favorable metabolic profile may not represent a causal relationship, but more likely is owing to uncontrolled confounding or owing to reverse causation.

\section{Supplementary information}

Supplementary information accompanies this paper at https://doi.org/10. 1186/s12937-019-0494-7.

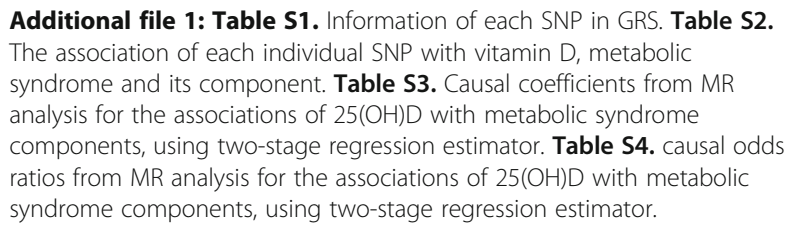

\section{Abbreviations}

25(OH)D: 25-hydroxyvitamin D; BMI: Body mass index; FPG: Fasting plasma glucose; GRS: Genetic risk score; HDL: High-density lipoprotein;

IV: Instrumental variable; MR: Mendelian randomization; MS: Metabolic syndrome; OR: Odds ratio; RCT: Randomized controlled trial; SNP: Single nucleotide polymorphism; TG: Triglycerides

\section{Acknowledgements}

The authors thank Xiaojin Wang and Bingshun Wang from the Department of Biostatistics and Shanghai Jiaotong University School of Medicine for data processing.

\section{Authors' contributions}

$Y L$ had full access to all the data in the study and takes responsibility for the integrity of the data and the accuracy of the data analysis. YL and NW were responsible for study concept and design. CC, YC, PW, FX, QL, HZ, and NW conducted the research. CC analyzed the data and drafted the manuscript, which was revised for important intellectual content by all authors. YL and NW are guarantors. All authors read and approved the final manuscript.

\section{Funding}

This study was supported by the National Natural Science Foundation of China (81600609); Shanghai JiaoTong University School of Medicine (2014); Science and Technology Commission of Shanghai Municipality

(16411971200, 16410723200); the Fourth Round of Three-Year Public Health Action Plan of Shanghai by the Shanghai Municipal Commission of Health and Family Planning (20164Y0079); and Municipal Human Resources Development Program for Outstanding Young Talents in Medical and Health Sciences in Shanghai (2017YQ053). 


\section{Availability of data and materials}

The datasets during and/or analyzed during the current study are available from the corresponding author on reasonable request.

\section{Ethics approval and consent to participate}

Ethical approval was obtained from the Ethics Committee of Shanghai Ninth People's Hospital, Shanghai Jiao Tong University School of Medicine. All participants provided written informed consent at enrollment.

\section{Consent for publication}

N/A

\section{Competing interests}

The authors declare that they have no competing interests.

\section{Received: 14 June 2019 Accepted: 14 October 2019}

\section{Published online: 28 October 2019}

\section{References}

1. Kaur J. A comprehensive review on metabolic syndrome. Cardiol Res Pract. 2014:2014:943162

2. O'Neill S, O'Driscoll L. Metabolic syndrome: a closer look at the growing epidemic and its associated pathologies. Obes Rev. 2015;16:1-12.

3. Lu J, Wang L, Li M, Xu Y, Jiang Y, Wang W, Li J, Mi S, Zhang M, Li Y, et al. Metabolic Syndrome Among Adults in China: The 2010 China noncommunicable disease surveillance. J Clin Endocrinol Metab. 2017;102: 507-15.

4. Fu J, Han L, Zhao Y, Li G, Zhu Y, Li Y, Li M, Gao S, Willi SM. Vitamin D levels are associated with metabolic syndrome in adolescents and young adults: The BCAMS study. Clin Nutr. 2019;38:2161-2167.

5. Zhu W, Heil DP. Associations of vitamin D status with markers of metabolic health: a community-based study in Shanghai, China. Diabetes Metab Syndr. 2018;12:727-32.

6. Chacko SA, Song Y, Manson JE, Van Horn L, Eaton C, Martin LW, McTiernan A, Curb JD, Wylie-Rosett J, Phillips LS, et al. Serum 25-hydroxyvitamin D concentrations in relation to cardiometabolic risk factors and metabolic syndrome in postmenopausal women. Am J Clin Nutr. 2011;94:209-17.

7. Ju SY, Jeong HS, Kim DH. Blood vitamin D status and metabolic syndrome in the general adult population: a dose-response meta-analysis. J Clin Endocrinol Metab. 2014:99:1053-63.

8. Weldegiorgis TZ, Hidru TH, Yang XL, Xia YL, Ma L, Li HH. Association between serum 25-hydroxyvitamin $D$ concentrations and metabolic syndrome in the middle-aged and elderly Chinese population in Dalian, northeast China: A cross-sectional study; 2019.

9. Al-Daghri NM, Alkharfy KM, Al-Saleh Y, Al-Attas OS, Alokail MS, Al-Othman A Moharram O, El-Kholie E, Sabico S, Kumar S, Chrousos GP. Modest reversal of metabolic syndrome manifestations with vitamin D status correction: a 12-month prospective study. Metabolism. 2012;61:661-6.

10. Wood AD, Secombes KR, Thies F, Aucott L, Black AJ, Mavroeidi A, Simpson WG, Fraser WD, Reid DM, Macdonald HM. Vitamin D3 supplementation has no effect on conventional cardiovascular risk factors: a parallel-group, double-blind, placebo-controlled RCT. J Clin Endocrinol Metab. 2012;97: 3557-68.

11. Salekzamani S, Mehralizadeh H, Ghezel A, Salekzamani Y, Jafarabadi MA Bavil AS, Gargari BP. Effect of high-dose vitamin D supplementation on cardiometabolic risk factors in subjects with metabolic syndrome: a randomized controlled double-blind clinical trial. J Endocrinol Investig. 2016; 39:1303-13.

12. Smith GD, Ebrahim S. 'Mendelian randomization': can genetic epidemiology contribute to understanding environmental determinants of disease? Int J Epidemiol. 2003;32:1-22

13. Haycock PC, Burgess S, Wade KH, Bowden J, Relton C, Davey Smith G. Best (but oft-forgotten) practices: the design, analysis, and interpretation of Mendelian randomization studies. Am J Clin Nutr. 2016;103:965-78.

14. Didelez V, Sheehan N. Mendelian randomization as an instrumental variable approach to causal inference. Stat Methods Med Res. 2007;16:309-30.

15. Wang N, Wang X, Han B, Li Q, Chen Y, Zhu C, Chen Y, Xia F, Cang Z Zhu $C$, et al. Is exposure to famine in childhood and economic development in adulthood associated with diabetes? J Clin Endocrinol Metab. 2015;100:4514-23.
16. Wang N, Wang X, Li Q, Han B, Chen Y, Zhu C, Chen Y, Lin D, Wang B, Jensen MD, Lu Y. The famine exposure in early life and metabolic syndrome in adulthood. Clin Nutr. 2017;36:253-9.

17. Chen C, Xu H, Chen Y, Chen Y, Li Q, Hu J, Liang W, Cheng J, Xia F, Wang C, et al. lodized salt intake and its association with urinary iodine, thyroid peroxidase antibodies, and thyroglobulin antibodies among urban Chinese. Thyroid. 2017;27:1566-73.

18. Xu Y, Wang $L$, He J, Bi Y, Li M, Wang T, Wang $L$, Jiang $Y$, Dai $M$, Lu J, et al. Prevalence and control of diabetes in Chinese adults. JAMA. 2013;310:948-59.

19. Chen C, Zhai H, Cheng J, Weng P, Chen Y, Li Q, Wang C, Xia F, Wang N, Lu Y. Causal link between vitamin $D$ and Total testosterone in men: a Mendelian randomization analysis. J Clin Endocrinol Metab. 2019;104:3148-56.

20. Alberti KG, Zimmet $P$, Shaw J, Group IDFETFC. The metabolic syndrome--a new worldwide definition. Lancet. 2005;366:1059-62.

21. Cuellar-Partida G, Williams KM, Yazar S, Guggenheim JA, Hewitt AW, Williams C, Wang JJ, Kho PF, Saw SM, Cheng CY, et al. Genetically low vitamin D concentrations and myopic refractive error: a Mendelian randomization study. Int J Epidemiol. 2017;46:1882-90.

22. Li SS, Gao LH, Zhang XY, He JW, Fu WZ, Liu YJ, Hu YQ, Zhang ZL. Genetically low vitamin $\mathrm{D}$ levels, bone mineral density, and bone metabolism markers: a Mendelian randomisation study. Sci Rep. 2016;6:33202.

23. Wang N, Chen C, Zhao L, Chen Y, Han B, Xia F, Cheng J, Li Q, Lu Y. Vitamin $\mathrm{D}$ and nonalcoholic fatty liver disease: Bi-directional Mendelian randomization analysis. EBioMedicine. 2018;28:187-93.

24. Vimaleswaran KS, Berry DJ, Lu C, Tikkanen E, Pilz S, Hiraki LT, Cooper JD, Dastani Z, Li R, Houston DK, et al. Causal relationship between obesity and vitamin D status: bi-directional Mendelian randomization analysis of multiple cohorts. PLoS Med. 2013;10:e1001383.

25. Lawlor DA, Harbord RM, Sterne JA, Timpson N, Davey Smith G. Mendelian randomization: using genes as instruments for making causal inferences in epidemiology. Stat Med. 2008;27:1133-63.

26. Leong A, Rehman W, Dastani Z, Greenwood C, Timpson N, Langsetmo L, Berger C, Metastroke, Fu L, Wong BY, et al. The causal effect of vitamin D binding protein (DBP) levels on calcemic and cardiometabolic diseases: a Mendelian randomization study. PLoS Med. 2014;11:e1001751.

27. Salekzamani S, Bavil AS, Mehralizadeh H, Jafarabadi MA, Ghezel A, Gargari $B P$. The effects of vitamin D supplementation on proatherogenic inflammatory markers and carotid intima media thickness in subjects with metabolic syndrome: a randomized double-blind placebo-controlled clinical trial. Endocrine. 2017:57:51-9.

28. Beveridge LA, Struthers AD, Khan F, Jorde R, Scragg R, Macdonald HM, Alvarez JA, Boxer RS, Dalbeni A, Gepner AD, et al. Effect of vitamin D supplementation on blood pressure: a systematic review and meta-analysis incorporating individual patient data. JAMA Intern Med. 2015:175:745-54.

29. Wang $H$, Xia N, Yang $Y$, Peng DQ. Influence of vitamin D supplementation on plasma lipid profiles: a meta-analysis of randomized controlled trials. Lipids Health Dis. 2012;11:42

30. Bolland MJ, Grey A, Gamble GD, Reid IR. The effect of vitamin D supplementation on skeletal, vascular, or cancer outcomes: a trial sequential meta-analysis. Lancet Diabetes Endocrinol. 2014;2:307-20.

31. Brondum-Jacobsen $P$, Benn M, Afzal S, Nordestgaard BG. No evidence that genetically reduced 25 -hydroxyvitamin $D$ is associated with increased risk of ischaemic heart disease or myocardial infarction: a Mendelian randomization study. Int J Epidemiol. 2015;44:651-61.

32. Manousaki D, Mokry LE, Ross S, Goltzman D, Richards JB. Mendelian randomization studies do not support a role for vitamin $D$ in coronary artery disease. Circ Cardiovasc Genet. 2016;9:349-56.

33. Afzal S, Brondum-Jacobsen P, Bojesen SE, Nordestgaard BG. Genetically low vitamin $\mathrm{D}$ concentrations and increased mortality: Mendelian randomisation analysis in three large cohorts. Bmj. 2014;349:96330.

34. Aytur SA, Jones SA, Stransky M, Evenson KR. Measuring physical activity in outdoor community recreational environments: implications for research, policy, and practice. Curr Cardiovasc Risk Rep. 2015;9. https://doi.org/10. 1007/s12170-014-0423-4.

35. Autier P, Mullie P, Macacu A, Dragomir M, Boniol M, Coppens K, Pizot C, Boniol M. Effect of vitamin D supplementation on non-skeletal disorders: a systematic review of meta-analyses and randomised trials. Lancet Diabetes Endocrinol. 2017:5:986-1004

36. Ooi EM, Afzal S, Nordestgaard BG. Elevated remnant cholesterol in 25 hydroxyvitamin D deficiency in the general population: Mendelian randomization study. Circ Cardiovasc Genet. 2014;7:650-8. 
37. Shinkyo R, Sakaki T, Kamakura M, Ohta M, Inouye K. Metabolism of vitamin D by human microsomal CYP2R1. Biochem Biophys Res Commun. 2004;324:451-7.

38. Cooper JD, Smyth DJ, Walker NM, Stevens H, Burren OS, Wallace C, Greissl C, Ramos-Lopez E, Hypponen E, Dunger DB, et al. Inherited variation in vitamin $D$ genes is associated with predisposition to autoimmune disease type 1 diabetes. Diabetes. 2011;60:1624-31.

39. Jones G, Prosser DE, Kaufmann M. 25-Hydroxyvitamin D-24-hydroxylase (CYP24A1): its important role in the degradation of vitamin D. Arch Biochem Biophys. 2012;523:9-18.

40. Vimaleswaran KS, Cavadino A, Berry DJ, Jorde R, Dieffenbach AK, Lu C, Alves AC, Heerspink HJ, Tikkanen E, Eriksson J, et al. Association of vitamin D status with arterial blood pressure and hypertension risk: a mendelian randomisation study. Lancet Diabetes Endocrinol. 2014;2:719-29.

41. Global Burden of Metabolic Risk Factors for Chronic Diseases Collaboration. Cardiovascular disease, chronic kidney disease, and diabetes mortality burden of cardiometabolic risk factors from 1980 to 2010: a comparative risk assessment. Lancet Diabetes Endocrinol. 2014;2:634-47.

42. Trajanoska K, Morris JA, Oei L, Zheng HF, Evans DM, Kiel DP, Ohlsson C, Richards JB, Rivadeneira F. Assessment of the genetic and clinical determinants of fracture risk: genome wide association and mendelian randomisation study. Bmj. 2018;362:k3225.

43. Ye Z, Sharp SJ, Burgess S, Scott RA, Imamura F, Langenberg C, Wareham NJ, Forouhi NG. Association between circulating 25-hydroxyvitamin $D$ and incident type 2 diabetes: a mendelian randomisation study. Lancet Diabetes Endocrinol. 2015;3:35-42.

\section{Publisher's Note}

Springer Nature remains neutral with regard to jurisdictional claims in published maps and institutional affiliations.

Ready to submit your research? Choose BMC and benefit from:

- fast, convenient online submission

- thorough peer review by experienced researchers in your field

- rapid publication on acceptance

- support for research data, including large and complex data types

- gold Open Access which fosters wider collaboration and increased citations

- maximum visibility for your research: over $100 \mathrm{M}$ website views per year

At $\mathrm{BMC}$, research is always in progress.

Learn more biomedcentral.com/submissions 